\title{
Aberrant methylation of multiple imprinted genes in embryos of tamoxifen-treated male rats
}

\author{
Neelam A Kedia-Mokashi, Leena Kadam, Mandar Ankolkar, Kushaan Dumasia and N H Balasinor \\ Neuroendocrinology Division, National Institute for Research in Reproductive Health (ICMR), Parel, \\ Mumbai 400 012, India \\ Correspondence should be addressed to N H Balasinor; Email: balasinorn@nirrh.res.in
}

\begin{abstract}
Genomic imprinting is an epigenetic phenomenon known to regulate fetal growth and development. Studies from our laboratory have demonstrated that treatment of adult male rats with tamoxifen increased postimplantation loss around mid gestation. Further studies demonstrated the aberrant expression of transcripts of several imprinted genes in the resorbing embryos at days 11 and 13 of gestation including IGF2. In addition, decreased methylation at the Igf2-H19 imprint control region was observed in spermatozoa and in resorbing embryos sired by tamoxifen-treated males. In this study, methylation analysis of the imprinted genes, which were found to be differentially expressed, was done using EpiTYPER in the spermatozoa of tamoxifen-treated rats and in postimplantation embryos sired by tamoxifen-treated rats. Differentially methylated regions (DMRs) for most imprinted genes have not been identified in the rats. Hence, initial experiments were performed to identify the putative DMRs in the genes selected for the study. Increased methylation at CpG islands present in the putative DMRs of a number of imprinted genes was observed in the resorbing embryos sired by tamoxifen-treated male rats. This increase in methylation is associated with the downregulation of most of these genes at the transcript level in resorbing embryos. No change in the methylation status of these genes was observed in spermatozoa. These observations suggest that a deregulation of mechanisms protecting unmethylated alleles from a wave of de novo methylation occurs following implantation. Reproduction (2013) $\mathbf{1 4 6} 155-168$
\end{abstract}

\section{Introduction}

Parental allele-specific expression of a subset of genes is known as genomic imprinting. Approximately 100 imprinted genes are known in mammals, and most of them have been implicated in embryo growth and development (Bartolomei \& Ferguson-Smith 2011). CpG methylation is a major component of the germline-specific epigenetic modifications implicated in monoallelic expression of imprinted genes. Imprinted genes contain differentially methylated regions (DMR), which ensure their allele-specific expression (Constancia et al. 1998). Methylation at primary DMRs is established in the germline, and once acquired, these imprints are maintained in all the somatic lineages (Constancia et al. 1998), whereas methylation at secondary DMRs is established after fertilization and could be tissue specific (Constancia et al. 1998). Four imprinted genes, lgf2-H19, Dlk1-Meg3 (Gt/2), Rasgrf1 and Zdbf2, are known to be methylated in the male germline (Arnaud \& Feil 2005, Kobayashi et al. 2009). In the male germline, methylation is initiated by embryonic day (E) 17.5 and is completed after birth by the pachytene stage of meiosis (Oakes et al. 2007). In the female germline, methylation is only initiated after birth during oocyte growth; imprints are acquired synchronously at different imprinted loci by metaphase II (Lucifero et al. 2004). Once acquired, the imprint marks are maintained and read throughout embryo development.

In addition to $\mathrm{CpG}$ methylation, non-CpG methylation, mainly involving methylation at $\mathrm{CpA}$ and $\mathrm{CpT}$ dinucleotides, was first demonstrated in cultured murine ES cells (Ramsahoye et al. 2000). Thereafter, non-CpG methylation was found primarily at $\mathrm{CpA}$ dinucleotides and to a lesser extent at CpTs dinucleotides, in both non-imprinted genes such as Nf1 (Haines et al. 2001) and imprinted genes (Tomizawa et al. 2011). A significant amount of non-CpG methylation has been reported in mouse oocytes, albeit to a lesser extent in blastocysts, and was negligible in sperm and E12.5 mouse embryos (Tomizawa et al. 2011). The functional significance of non-CpG methylation is, however, not yet known. In this study, we therefore restricted ourselves to analyzing CpG methylation at imprinted genes.

In recent years, evidence that methylation defects in sperm can cause aberrant embryo development is accumulating (Nanassy \& Carrell 2008, Jenkins \& Carrell 2012). In rodents, paternal exposure to drugs or environmental chemicals has been associated with epimutations and defects in embryo development. Studies by 
Anway et al. (2005) have demonstrated that exposure of pregnant female rats to endocrine disruptors like vinclozolin (an antiandrogenic compound) or methoxychlor (an estrogenic compound), before and during embryonic sex determination, resulted in male offspring with reduced spermatogenetic capacity. The $\mathrm{F}_{1}$ adult males exhibited reduced testicular germ cell number and viability, and an increased incidence of infertility. The testicular phenotype appeared to be transmitted, transgenerationally through the $\mathrm{F}_{1}-\mathrm{F}_{4}$ generations, mainly involving alterations in the DNA methylation patterns of the male germline. Recently, it has been reported that the sperm obtained from methoxychlor-treated adult mice showed a decrease in methylation at the Meg3 DMR and an increase in methylation at Peg3, Snrpn, and Mest DMRs (Stouder \& Paoloni-Giacobino 2011).

Chronic administration of cytosine analogs 5-azacytidine and 5-aza-2-deoxycytidine to adult male rats has been associated with decreased sperm counts, abnormal testicular histology, and an increase in preimplantation embryo loss (Doerksen \& Trasler 1996, Doerksen et al. 2000, Kelly \& Trasler 2004). In addition, treatment with 5-aza-2-deoxycytidine also induced DNA hypomethylation in rat male germ cells (Kelly et al. 2003). Sperm from 5-aza-2-deoxycytidine-treated male mice also exhibited a decrease in methylation of the Rasgrf1 DMR (Oakes et al. 2007). These studies in rodents demonstrate that the acquisition and maintenance of DNA methylation patterns in the male germline are crucial for spermatogenesis and embryogenesis.

Treatment with drugs such as tamoxifen has been shown to reduce fertility and affect the sperm quality of adult male rats (Gill-Sharma etal. 1993, Motrich et al. 2007). Tamoxifen, a selective estrogen receptor modulator, is widely used for the treatment of breast cancer and is prescribed to patients with gynecomastia and oligozoospermia (Noci et al. 1985, Parker et al. 1986, Cuzick et al. 2003). Studies from our laboratory have shown that tamoxifen treatment of adult male rats at a dose of $0.4 \mathrm{mg} / \mathrm{kg}$ per day (equivalent to human tamoxifen therapy) for 60 days results in an increase in pre- and postimplantation loss ( $\mathrm{POL}$ ) but the rate of fertilization is unaltered (Balasinor et al. 2001). Histology of the resorptions (at E20) showed the presence of trophoblast outgrowths, which are suggestive of early placentation, leading us to conclude that the POL might have commenced around E9-E11 (Balasinor et al. 2002). Embryos at E13 have just started resorbing and are not dead; hence, we refer to them as 'resorbing embryos' hereafter.

We previously reported a decrease in methylation at the Igf2-H19 imprinting control region (ICR) in sperm and embryos sired by tamoxifen-treated male rats, as well as a decrease in the lgf2 transcript and protein levels (Kedia et al. 2004, Pathak et al. 2009, 2010). Furthermore, microarray studies comparing the expression profiles of normal vs resorbing embryos at E11 and E13 from both control and treated groups showed downregulation of a number of other imprinted genes: Plag/1, Peg3, Peg5,
Ascl2, Cdkn1c, Phlda2, Igf2r, Grb10, Gpc3 and Sgce (Kedia-Mokashi et al. 2011). In this study, we aimed to decipher the cause of the aberrant expression of imprinted genes in these embryos. We studied the methylation status of nine imprinted genes, four known to be expressed from the paternal allele (DIk1, Plagl1, Peg5 and Peg3) and five known to be expressed from the maternal allele (Igf2r, Grb10, Kcnq1, Ascl2 and Cdkn1c) in the sperm of tamoxifen-treated rats and the embryos (at E13) sired by them. The global DNA methylation levels in these embryos were also assessed.

\section{Materials and Methods}

\section{Animals}

Randomly bred adult male (75-day-old) and female (90-dayold) rats of the Holtzman strain weighing 250-300 g and maintained at the temperature of $22-23{ }^{\circ} \mathrm{C}$, humidity $50-55 \%$, and $14 \mathrm{~h}$ light:10 $\mathrm{h}$ darkness cycle were used for the study. Food and water were available ad libitum. The study was approved by the Institute's Animal Ethics Committee for 'Care and Use of Laboratory Animals for Biomedical Research'.

\section{Treatment and mating schedule}

Tamoxifen citrate tablets (Hetero Healthcare Ltd, Hyderabad, India) containing $10 \mathrm{mg}$ tamoxifen was uniformly suspended in water by sonication and administered orally to adult male rats. Tamoxifen was administered at a concentration of $0.4 \mathrm{mg} / \mathrm{kg}$ day, 5 days a week for 60 days, between 0900 and $1100 \mathrm{~h}$ via a rat feeding tube. Control male rats were administered water only. Thirty-eight male rats per group were used in the study. Control or tamoxifen-treated male rats were mated with normal cycling female rats a week before the completion of the 60-day treatment regimen. The mating design used a ratio of one male to two females. The day of sperm-positive vaginal smear was considered as day ' 0 ' of gestation. Gravid females were killed on $\mathrm{E} 13$, by asphyxiation with $\mathrm{CO}_{2}$. The number of implantation sites, normal and resorbing embryos (distinguished based on the size), were noted, snap-frozen, and stored at $-80{ }^{\circ} \mathrm{C}$ until further use. The POL was calculated using the following formula:

$$
\frac{\text { No. of implantation sites }- \text { No. of normal embryos }}{\text { No. of implantation sites }} \times 100
$$

\section{Sample collection and DNA extraction}

\section{Sperm preparation}

After mating, control or treated male rats were perfusion cleared by $0.01 \mathrm{M}$ PBS, $\mathrm{pH} 7.4$, containing $1 \mathrm{ml}$ heparin (5000 IU) through the heart (Hess 1990). The epididymis was excised and collected in sterile PBS. Sperm were collected from the cauda epididymis. The cauda were thoroughly washed in PBS $(136 \mathrm{mM} \mathrm{NaCl}, 2.6 \mathrm{mM} \mathrm{KCl}, 6.4 \mathrm{mM}$ $\mathrm{Na}_{2} \mathrm{HPO}_{4}$, and $1.28 \mathrm{mM} \mathrm{KH_{2 }} \mathrm{PO}_{4}, \mathrm{pH} 7.4$ ), and after giving three to four superficial cuts, the cauda were incubated at $37^{\circ} \mathrm{C}$ 
for 30-45 min. The supernatant containing sperm was filtered through a $40 \mu \mathrm{m}$ cell strainer, centrifuged, and aliquots of $10 \times 10^{6}$ sperm were stored at $-80^{\circ} \mathrm{C}$ (Pathak et al. 2009).

DNA was extracted from $10 \times 10^{6}$ sperm, suspended in $100 \mu \mathrm{l}$ PBS (supplied in the kit), and processed from the sperm lysis step onward, using HiPurA Sperm Genomic DNA Purification Spin Kit (HiMedia, Mumbai, India) according to manufacturer's protocol. The DNA was eluted in HPLC grade water and the concentration was determined spectrophotometrically. Sperm samples from ten control rats and nine tamoxifen-treated rats amounting to a total of 19 samples were used for extraction.

\section{Embryos}

Normal embryos sired by three different control or tamoxifentreated male rats were excised from the uterus on an ice pack and the embryonic part and placenta of each implant were processed individually for extraction. Three resorbing embryos sired by three different tamoxifen-treated male rats were excised from the uterus on an ice pack and the entire implant as a whole was used for extraction. The normal and resorbing embryos used for DNA extraction were obtained from the same litter. Therefore, the total of 15 samples processed for DNA extraction comprised control samples, three normal embryos and three normal placentae, and treated samples, three normal embryos, three normal placentae, and three resorbing embryos.

DNA was extracted from individual embryos $(\sim 25 \mathrm{mg}$ tissue) using HiPurA Mammalian Genomic DNA Purification Spin Kit (HiMedia) according to the manufacturer's protocol. The DNA was eluted in HPLC grade water and the concentration was determined spectrophotometrically.

\section{Identification of putative DMRs and primer design}

For identifying the putative DMRs, BLAST of known mouse DMR sequences was performed with the rat genomic sequence database and the web-based software MethPrimer was employed to determine the CpG island (CGI) location (http://www.urogene.org/methprimer/). The details of identification of rat putative DMR sequences are described below.
The paternally expressed genes included are Dlk1 promoter: a CGI of $\sim 116 \mathrm{bp}$ was present in the mouse Dlk1 gene. The corresponding region in the rat is conserved to $91 \%$ identity and harbors a CGI of $\sim 119$ bp (Fig. 1A, left panel). Dlk1-Meg3 intergenic DMR (IGDMR): a CGI of $195 \mathrm{bp}$ was identified in the mouse Dlk1-Meg3 gene cluster (AJ320506). The corresponding region in the rat Dlk1-Meg3 gene cluster (NW_001084847) is conserved to $77 \%$ identity and harbors a CGI of $\sim 396 \mathrm{bp}$ (Fig. 1A, right panel). Peg5: a CGI of $\sim 760$ bp was identified in the mouse Peg5 gene (AF303656). The corresponding region in the rat Peg5 gene (NW_001084817) is conserved to 91\% identity and harbors a CGI $\sim 700$ bp (Fig. 1B). Plag/1: a CGI of $\sim 470$ bp was identified in the mouse Plag/1 gene (AJ308559). The corresponding region in the rat Plag/1 gene (NW_001084746) is conserved to $84 \%$ identity and harbors a CGI of $\sim 600 \mathrm{bp}$ (Fig. 1C). Peg3: two CGls of $\sim 160$ and $\sim 190$ bp were identified in the mouse Peg3 gene (AF105262). The corresponding region in the rat Peg3 gene (NW_001084760) is conserved to 94\% identity and harbors two CGls of $\sim 220$ and $\sim 330$ bp (Fig. 1D).

The maternally expressed genes included are Grb10: a CGI of $\sim 1065 \mathrm{bp}$ was identified in the mouse Grb10 gene (AL663087). The corresponding region in the rat Grb10 gene (NW_001084694) is conserved to 88\% identity and harbors a CGI of $\sim 1100 \mathrm{bp}$ (Fig. 2A). Igf2r: a CGl of $\sim 950 \mathrm{bp}$ was identified in the mouse $\operatorname{lgf} 2 r$, region 1 (L06445). The corresponding region in the rat Igf2r gene (NW_001084751) is conserved to $92 \%$ identity and harbors a CGI of $\sim 895 \mathrm{bp}$ (Fig. 2B). Four CGIs (nucleotide positions 800-2300) were observed in the mouse Igf2r, region 2 (L06446). However, the corresponding region was found to be very poorly conserved in the rat, with a sequence coverage of only $53 \%$ and identity of $80 \%$. Hence, we did not select this region for our study. Cdkn1c: a CGI of $\sim 1495$ bp was identified in the mouse Cdkn1c-Kcnqot1 domain (AP001293). The corresponding region in the rat sequence is conserved to $95 \%$ identity and harbors a CGI of 1425 bp (Fig. 2C, left panel). Kcnq1 DMR: a CGI of $\sim 320$ bp was identified in the mouse Cdkn1c-Kcnqot1 domain (AP001295). The corresponding region in the rat Cdkn1c-Kcnqot1 domain (NW_001084774) is conserved to $78 \%$ identity and harbors a CGI of $\sim 290$ bp (Fig. 2C, right
A

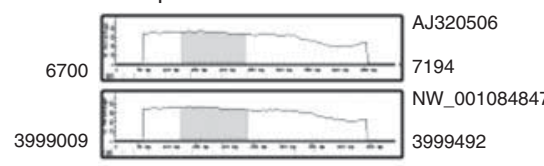

B Peg5

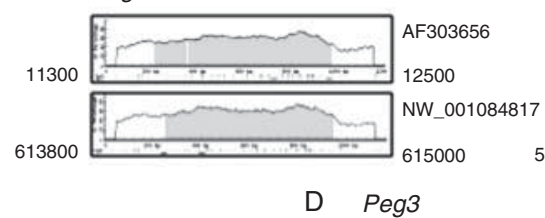

D $\quad P e g 3$

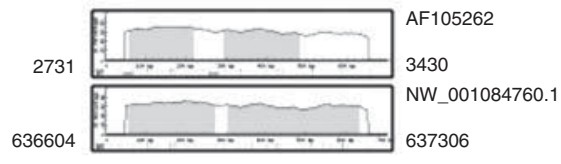

DIk1-Meg3 IGDMR

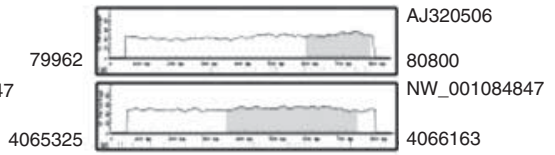

C Plagl1

1029

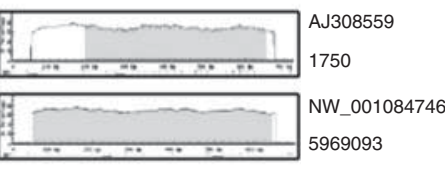

Figure 1 Identification of CGIs in paternally expressed imprinted genes in the rat. The CGls in the mouse sequence (upper panel) and the corresponding CGI identified in the rat sequence (lower panel) using MethPrimer. The CGls in Dlk1 IGDMR (A, right panel); DIk1 promoter (A, left panel); Peg5 (B), Plagl1 (C), and Peg3 (D) genes were used for the EpiTYPER analysis. Additional details are given in the Materials and Methods section. 


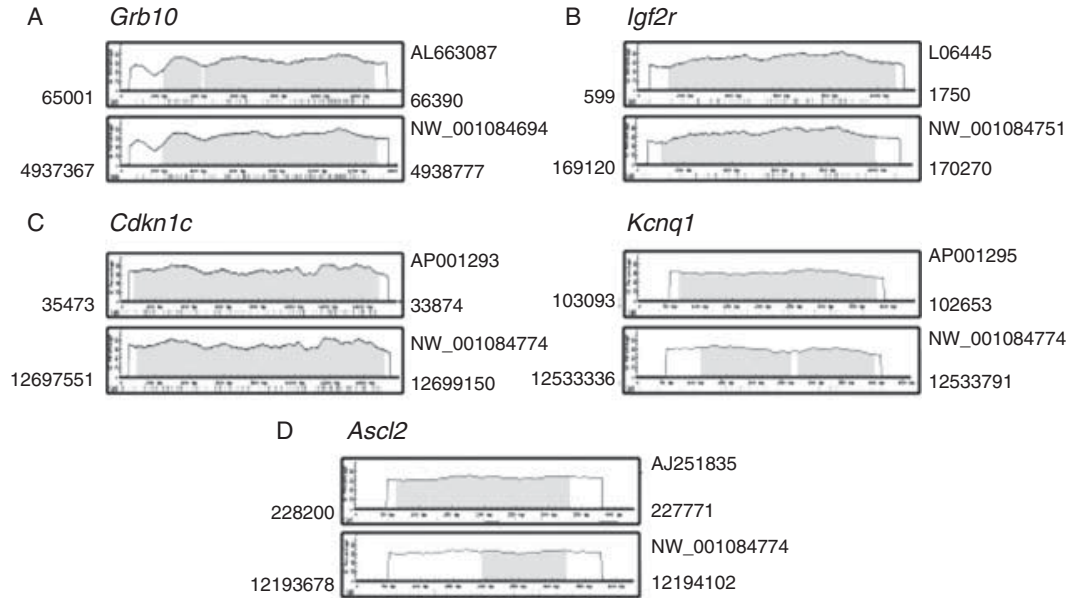

Figure 2 Identification of CGls in maternally expressed imprinted genes in the rat. The CGIs in the mouse sequence (upper panel) and the corresponding CGI identified in the rat sequence (lower panel) using MethPrimer. The CGIs in Grb10 (A), Igf2r (B), Kcnq1 DMR (C, left panel), Cdkn1c (C, right panel), and Ascl2 (D) genes were used for the EpiTYPER analysis. Additional details are given in the Materials and Methods section. panel). Ascl2: a CGI of $\sim 270$ bp was identified in the mouse Cdkn1c-Kcnqot1 domain (AJ251835). The corresponding region in the rat sequence is conserved to $92 \%$ identity and harbors a CGI of $\sim 135 \mathrm{bp}$ (Fig. 2D).

Primers were designed using EpiDesigner software (Sequenom, San Diego, CA, USA) to cover the regions with the most CpG sites. A T7-promoter tag (CAGTAATACGACTCACTATAGGGAGAAGGCT) was added to the reverse primer to obtain an appropriate product for in vitro transcription and a 10 mer-tag (AGGAAGAGAG) was added to the forward primer to balance the PCR primer length.

\section{Bisulfite modification of DNA}

The bisulfite conversion of $1 \mu \mathrm{g}$ of genomic DNA was done using the EZ-96 DNA Methylation Kit (Zymo Research, Irvine, CA, USA) according to the manufacture's protocol with minor modifications. After addition of the bisulfite reagent, samples were placed in a thermal cycler for a cycling incubation using Zymo's 'Alternative Cycling Protocol', which involves denaturation at $95{ }^{\circ} \mathrm{C}$ for $30 \mathrm{~s}$ and conversion at $50{ }^{\circ} \mathrm{C}$ for $15 \mathrm{~min}$. This was repeated for 20 cycles followed by incubation at $0-4{ }^{\circ} \mathrm{C}$ (on the thermal cycler) for $10 \mathrm{~min}$. The postincubation processing was done as detailed in the user manual. The modified DNA was eluted in HPLC water and stored at $-20{ }^{\circ} \mathrm{C}$ for later use.

\section{EpiTYPER procedure}

The bisulfite-treated genomic DNA was amplified using Taq DNA polymerase (Roche Diagnostics) in 384-well plates, for the regions described earlier. The thermal cycling conditions involved initial denaturation at $95^{\circ} \mathrm{C}$ for $4 \mathrm{~min}$ followed by 45 cycles of $95{ }^{\circ} \mathrm{C}$ for $20 \mathrm{~s}$, annealing at optimal temperature for $30 \mathrm{~s}$, and extension at $72{ }^{\circ} \mathrm{C}$ for $1 \mathrm{~min}$. Final extension took place at $72{ }^{\circ} \mathrm{C}$ for $3 \mathrm{~min}$. PCR products were further processed for MassARRAY analysis using MassCLEAVE T7 Kit (Sequenom). Unincorporated dNTPs were dephosphorylated by adding $1.7 \mu \mathrm{H}_{2} \mathrm{O}$ and $0.3 \mathrm{U}$ shrimp alkaline phosphatase followed by incubation at $37^{\circ} \mathrm{C}$ for $40 \mathrm{~min}$ and heat inactivation of shrimp alkaline phosphatase at $85^{\circ} \mathrm{C}$ for $5 \mathrm{~min}$. For the in vitro transcription, PCR product $(2 \mu \mathrm{l})$ was used as a template in a $5 \mu \mathrm{l}$ transcription reaction. T7 RNA and DNA polymerases
$(20 \mathrm{U})$ were used to incorporate dTTP in the transcripts. Ribonucleotides were used at $1 \mathrm{mmol} / \mathrm{l}$ and the dNTP substrate at $2.5 \mathrm{mmol} / \mathrm{l}$. RNase A enzyme was added in the same step for base-specific cleavage of the RNA transcripts (T-cleavage assay). The T-cleavage reaction was carried out at $37^{\circ} \mathrm{C}$ for $3 \mathrm{~h}$ and further diluted with $\mathrm{H}_{2} \mathrm{O}$ to a final volume of $27 \mu \mathrm{l}$. Sample conditioning of the phosphate backbone was achieved by adding $6 \mathrm{mg}$ Clean Resin from the Clean Resin Kit (Sequenom) and $22 \mathrm{nl}$ cleavage reaction was robotically dispensed onto a 384-well sample chips (SpectroCHIP Arrays, Sequenom) using the MassARRAY Nanodispenser. The SpectroCHIPs were then placed into the Sequenom MassARRAY Compact Analyzer. The data were collected and analyzed using the EpiTYPER software v1.0.2 (Sequenom).

\section{EpiTYPER data analysis}

The spectra quality (peak height and confidence score) for each reaction was examined using the EpiTYPER program. Fragments with a mass of 1700 Da or less were removed from analysis in this study as they are more likely to match with other small fragments and lead to inaccurate peak calls (Coolen et al. 2007). CpG sites that gave no data in $>30 \%$ of the samples were discarded. Finally, individual samples were removed if they had no data at $30 \%$ or more of the CpG sites within the amplicon. Following filtering to exclude poor-quality data, the methylation percentages at each CpG site were averaged for each tissue within the control/treated groups using Microsoft Excel to generate the percentage methylation for the amplicon. The mean and s.D. of percentage methylation for each group of tissues was calculated using Microsoft Excel. The statistical significance between groups was assessed by the Student's t-test $(P \leq 0.05$ was considered significant). The bisulfite modification and EpiTYPER experiment were done in collaboration with Ace Probe, New Delhi (Sequenom service provider in India).

\section{EpiTYPER study}

A pilot experiment was done using the primers mentioned in Table 1 in order to confirm their DMR methylation status using DNA from embryo and sperm from a control rat (if the region is a gametic DMR, then the sperm would be either 
Table 1 Rat primer sequences used for EpiTYPER analysis.

\begin{tabular}{|c|c|c|}
\hline $\begin{array}{l}\text { Gene } \\
\text { symbols }\end{array}$ & Primer sequences $^{\mathrm{a}}\left(5^{\prime}-3^{\prime}\right)$ & $\begin{array}{c}\begin{array}{c}\text { Size } \\
\text { of PCR } \\
\text { product } \\
\text { (bp) }\end{array} \\
\end{array}$ \\
\hline Dlk1-Meg3 & F-TAGTGTAGGTTTGGTGTGGTATAGA & 396 \\
\hline Dlk1 & $\begin{array}{l}\text { F-GTTTTTTTGTTTTTGTTGGTTTT } \\
\text { R-AAATACCTCCCAATACAATCTCCTT }\end{array}$ & 358 \\
\hline Peg5 & $\begin{array}{l}\text { F-GAGATTTGTTTAGGGATTTGTTTTTT } \\
\text { R-CACCCTTCCAAAAAATTCTACTCTA }\end{array}$ & 211 \\
\hline Peg3 & $\begin{array}{l}\text { F-GAGAGATGTTTATTTTGGGTTGGT } \\
\text { R-CAATCTACAACCTTATCAATCACCC }\end{array}$ & 263 \\
\hline Plag/1 & $\begin{array}{l}\text { F-GTTATTTTTTTTGGTTGGTTTGTTG } \\
\text { R-CAACACCAAAACTATCACTTACCTAT }\end{array}$ & 304 \\
\hline $\operatorname{lgf} 2 r$ & $\begin{array}{l}\text { F-AGGATTTTAGAAAAGTTGATTTGTT } \\
\text { R-AACCTAACAACCCCAAAATTTAATC }\end{array}$ & 232 \\
\hline Grb10 & $\begin{array}{l}\text { F-AGATTTTGGGAGGTAAATTTTTTTTT } \\
\text { R-AAATCTATACTAACCAACTCTCCAAA }\end{array}$ & 130 \\
\hline KCnq1 DMR & $\begin{array}{l}\text { F-GAGAGTTTTTTTTGTTTAGTTTGGTTTTT } \\
\text { R-CAATAAATTCATCTCTACTTCTAACCA }\end{array}$ & 190 \\
\hline$C d k n 1 c$ & $\begin{array}{l}\text { F-GAGATTTGTTTAGGGATTTGTTTTT } \\
\text { R-TTCAACTTCCAACAAAATATACCTCTT }\end{array}$ & 385 \\
\hline Ascl2 & $\begin{array}{l}\text { F-GGTTTTGGTGTTTAGTTTTTAAGTT } \\
\text { R-AAAAAAACACAAATATACTCCTACAAT }\end{array}$ & 394 \\
\hline
\end{tabular}

$F$, forward primer; $R$, reverse primer.

aplease refer to Materials and Methods section for details of primer design.

hypomethylated or hypermethylated and the embryos would be partially methylated (40-50\%)).

A total of ten amplicons from nine genes were selected for the final experiment. The ten amplicons were from DIk1-Meg3 IGDMR, Dlk1, Peg5, Plagl1, Peg3, Grb10, Igf2r, Kcnq1 DMR, $C d k n 1 c$, and $A s c l 2$ genes. These amplicons were assayed in 19 sperm DNA samples and 15 embryonic DNA samples (normal embryo, normal placenta, and resorbing embryo) from control and tamoxifen-treated group, along with water controls. The EpiTYPER procedure and data analysis were performed as described above. The results of the pilot experiment and the final study are described below.

\section{Bisulfite sequencing PCR}

DNA ( $1 \mu \mathrm{g}$ ) obtained from sperm (as mentioned earlier) was modified using CpGenome Fast DNA Modification kit (Chemicon-Millipore, Billerica, MA, USA) according to the manufacturer's recommendations. The modified DNA was resuspended in HPLC grade water and immediately stored at $-20{ }^{\circ} \mathrm{C}$ until further use. The completion of the bisulfite modification of sperm DNA was confirmed by PCR with wildtype primer ' $\mathrm{W}$ ', which anneals to any DNA (methylated or unmethylated) that has not undergone bisulfite modification. The PCR was performed in $25 \mu \mathrm{l}$ reaction volume containing reaction buffers (FastStart PCR Master Kit from Roche Applied Science) and $10 \mathrm{pM}$ each of forward primers 5'-GATATCCTGTGGCGAGGGTA-3' and reverse primers $5^{\prime}$ GCCTCAAGGCAGTGGTTTAC-3' for Dlk1-Meg3 gene cluster and $80 \mathrm{ng}$ of the template. Thermal cycling conditions included initial denaturation at $94{ }^{\circ} \mathrm{C}$ for $5 \mathrm{~min}$ and then 35 cycles of denaturation at $94{ }^{\circ} \mathrm{C}$ for $1 \mathrm{~min}$, annealing at $51.5^{\circ} \mathrm{C}$ for $1 \mathrm{~min}$, extension at $72{ }^{\circ} \mathrm{C}$ for $1.5 \mathrm{~min}$, and final extension at $72{ }^{\circ} \mathrm{C}$ for $15 \mathrm{~min}$. The PCR products were resolved on $1 \%$ agarose gel.
The bisulfite-modified DNA, from sperm samples of three controls and three tamoxifen-treated rats, was PCR amplified in $25 \mu \mathrm{l}$ reaction volume containing reaction buffers (Hot Start PCR Mix from Roche Applied Science) and $25 \mathrm{pM}$ each of forward primer (5'-TAGGTTTGGTGTGGTATAGATATA-3') and reverse primers $\left(5^{\prime}\right.$-AATATATACCTCAAAACAATAATTTA- $\left.3^{\prime}\right)$ for the DIk1-Meg3 IGDMR and $80 \mathrm{ng}$ the template. Thermal cycling conditions included initial denaturation at $94{ }^{\circ} \mathrm{C}$ for $5 \mathrm{~min}$ and then 35 cycles of denaturation at $94{ }^{\circ} \mathrm{C}$ for $1 \mathrm{~min}$, annealing at $56{ }^{\circ} \mathrm{C}$ for $1 \mathrm{~min}$, extension at $72{ }^{\circ} \mathrm{C}$ for $1.5 \mathrm{~min}$, and final extension at $72{ }^{\circ} \mathrm{C}$ for $15 \mathrm{~min}$. The PCR products were gel purified and cloned into pCR 2.1 TOPO cloning vector (Invitrogen). Eight to ten clones per sample were sequenced on ABI Prism DNA Sequencer version 3.7 (Perkin Elmer, Norwalk, CT, USA). DNA methylation data obtained from sequencing were analyzed by quantitative methylation analysis (QUMA). For individual CpG sites, the percentage of CpG sites methylated to the total number of CpG sites assessed for that site was estimated and expressed as mean \pm s.D. The extent of methylation at individual CpG sites at the DIk1-Meg3 IGDMR in each group was analyzed by Student's $t$-test $(P \leq 0.05$ was considered significant).

\section{Global DNA methylation status of embryos}

The global DNA methylation status of postimplantation embryos was assessed with Methylamp Global DNA Methylation Quantification Kit (Epigentek, Brooklyn, NY, USA). A standard curve containing 6.25, 12.5, 25, 50, and $100 \mathrm{ng}$ methylated DNA control (positive) was prepared from a $100 \mu \mathrm{g} / \mathrm{ml}$ stock solution diluted with DNA binding solution. To eight-well assay strips, standards (concentrations given above) or samples (200 ng genomic DNA isolated from embryos) were added in duplicates, the volume in all wells adjusted to $30 \mu \mathrm{l}$ with DNA binding solution, and the contents were mixed thoroughly. For the blank, $30 \mu \mathrm{l}$ DNA binding solution was added to the wells instead of DNA. The strip wells were incubated at $37^{\circ} \mathrm{C}$ for $2 \mathrm{~h}$ followed by incubation at $60{ }^{\circ} \mathrm{C}$ for $30 \mathrm{~min}$ to evaporate the solution and dry the wells. The remaining steps were followed as described by the manufacturer, except that after the addition of primary antibody $(1 \mathrm{mg} / \mathrm{ml})$ the plate was incubated at $4{ }^{\circ} \mathrm{C}$ overnight and after addition of secondary antibody $(400 \mu \mathrm{g} / \mathrm{ml})$ the plate was incubated at room temperature for $1 \mathrm{~h}$. The absorbance was read on a microplate reader at $450 \mathrm{~nm}$. The optical density (OD) values were plotted against the amount of methylated DNA control standards, the slope of the plot was determined, and then the amount of methylated DNA in samples was calculated using the following formula:

$$
\begin{gathered}
\text { Methyl DNA }(\mathrm{ng})=\frac{\text { OD }(\text { sample }- \text { blank })}{\text { Slope }} \\
\text { Methylation }(\%)=\frac{\text { Methyl DNA amount }}{\text { Sample DNA amount added }} \times 100
\end{gathered}
$$

The mean \pm s.D. of percentage methylation levels in embryos sired by control and tamoxifen-treated male rats $(n=3)$ was analyzed by Student's $t$-test $(P \leq 0.05$ was considered significant). 
A

(i)

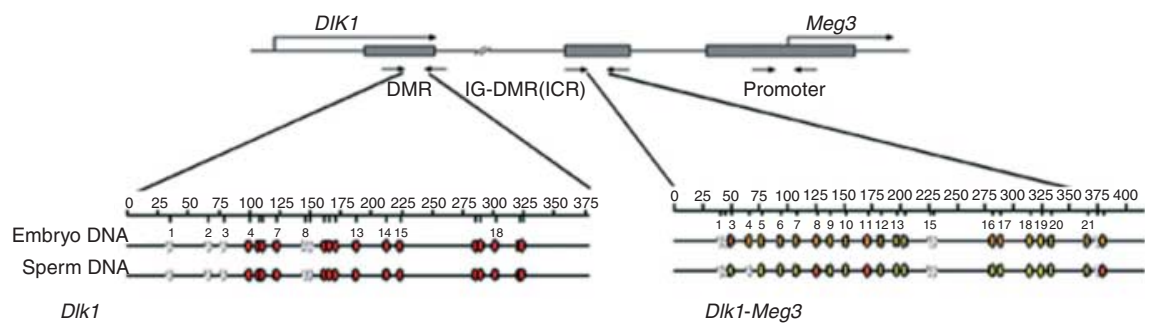

(ii)

(iii)
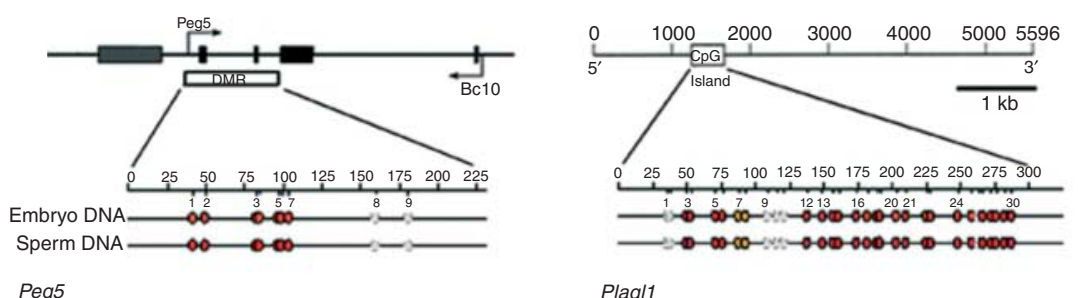

Plagl1

(iv)

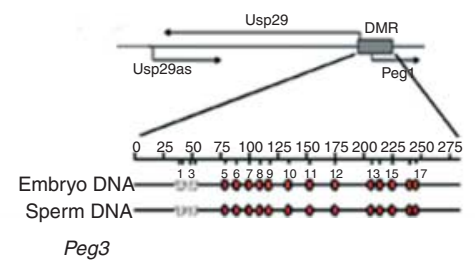

B

(i)

(ii)

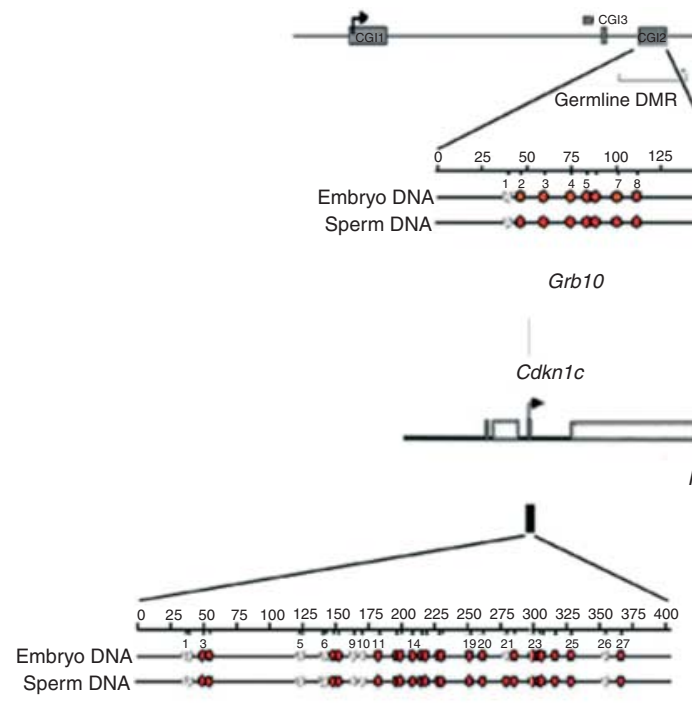

Cdkn1c

(iii)
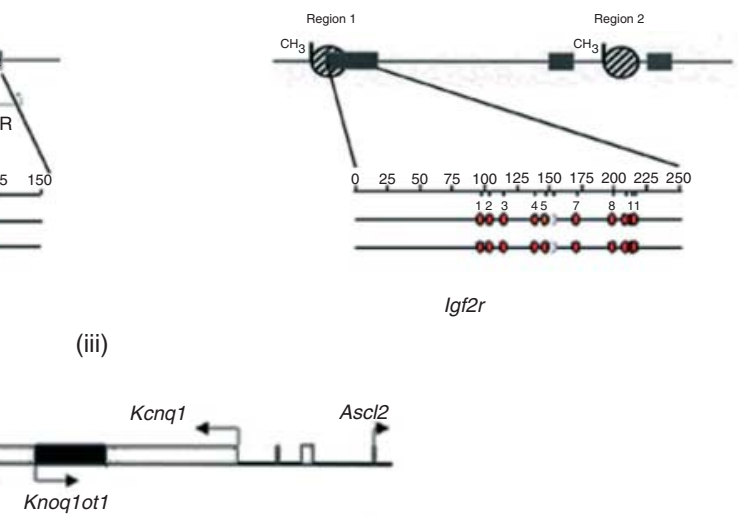

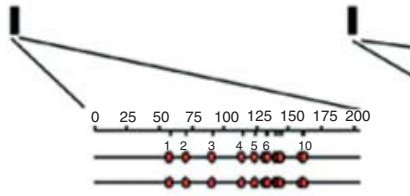

Kenq1
$0 \quad 255075100125150175200225250275300325350$

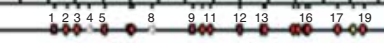

$\rightarrow-000-0$

Ascl2

$0 \% \$ 000000000100 \%$ Not analyzed: 


\section{Results}

\section{Postimplantation embryo loss on paternal tamoxifen treatment}

A significant increase in POL was observed in tamoxifentreated males when compared with controls $(P \leq 0.05)$. The mean \pm S.E.M. of percentage POL (per male) in the tamoxifen-treated group was found to be $10 \pm 2$, while in the control group, the percentage POL (per male) was found to be $3 \pm 0.68$ ( $n=38$ male rats and each male was mated with at least two female rats in both the groups). This is in confirmation with our earlier studies (Kedia et al. 2004, Pathak et al. 2009, 2010, Kedia-Mokashi et al. 2011).

\section{Identification of DMRs at paternally expressed imprinted genes and their methylation in embryos sired by tamoxifen-treated rats}

Except for Igf2-H19 DMR, the DMRs for other paternally expressed imprinted genes have not been reported in the rat, so we checked the homology of known mouse DMR sequences with the rat genomic sequence database and also confirmed the presence of $\mathrm{CGl}$ in these regions. In addition, a pilot study was conducted to find out whether the regions selected for the study were indeed differentially methylated.

We classified $\sim 0-10 \%$ methylation as hypomethylation, $\sim 40-50 \%$ as partial methylation, and $90-100 \%$ as hypermethylation. Based on this classification, if the region is a gametic DMR, then it should be either hypomethylated or hypermethylated in sperm and partially methylated in embryos. The details of the CGI and amplicons used in the experiment are described in the Materials and Methods section. The results of the pilot study are described below.

The $8 \mathrm{~kb}$-long IGDMR located $\sim 15 \mathrm{~kb}$ upstream of Meg3 gene and $70 \mathrm{~kb}$ downstream of mouse Dlk1 promoter is hypermethylated in sperm and hypomethylated in oocytes (Takada et al. 2002). A total of 24 CpGs located within a CGI of $\sim 396 \mathrm{bp}$ in the rat Dlk1 gene were found to be partially methylated in embryos and hypermethylated in sperm, suggesting it to be a DMR (Fig. 3A-i, right panel). Previously, we had reported downregulation of Dlk1 transcripts in the resorbing embryos (Kedia-Mokashi et al. 2011); hence, in this study, we also assessed methylation status of Dlk1 promoter. A total of 20 CpGs located within a CGI of $\sim 119 \mathrm{bp}$ in the rat Dlk1 gene were found to be hypomethylated in both embryo and sperm (Fig. 3A-i, left panel).

John et al. (2001) identified a CGl in the mouse Peg5/ Nnat gene spanning exon 1 and extending into intron 2, which was methylated on the maternal allele. A total of nine CpGs located within a CGI of $\sim 700 \mathrm{bp}$ in the rat Peg5 gene were found to be partially methylated in embryos and hypomethylated in sperm, suggesting it to be a DMR (Fig. 3A-ii). Smith et al. (2002) identified an extensive DMR of $\sim 1586 \mathrm{bp}$ in the mouse Plag/1 gene that was hypermethylated on maternal alleles and hypomethylated on the paternal alleles. A total of 31 CpGs located within a CGI of $\sim 600 \mathrm{bp}$ in the rat Plag/1 gene were found to be partially methylated in embryo and hypomethylated in sperm, suggesting it to be a DMR (Fig. 3A-iii). The $5 \mathrm{~kb}$ region surrounding first exon of Peg3 and Usp29 genes was found to contain a CGI that is hypermethylated maternally and hypomethylated on the paternal allele (Li et al. 2000, Lucifero et al. 2002). A total of 17 CpGs located within the CGls of $\sim 220$ and $\sim 330$ bp in the rat Peg3 gene were found to be partially methylated in embryos and hypomethylated in sperm, suggesting it to be a DMR (Fig. 3A-iv).

The methylation status of the above-mentioned amplicons was assessed in embryos sired by tamoxifen-treated male rats (Fig. 4A). A significant increase in methylation was observed at the DIk1-Meg3 DMR in the resorbing embryos from the treated group when compared with normal embryos/placentae from both the groups (Fig. 4A-i). Similarly, a significant increase in methylation was also observed at the CGI within the DIk1 promoter in the resorbing embryos from the treated group (Fig. 4A-ii). A significant increase in methylation was observed at the Peg5 DMR in the resorbing embryos from the treated group when compared with normal embryos from both groups (Fig. 4A-iii). A significant decrease in methylation was observed at the Plagl1 DMR in the normal embryos from treated group when compared with those from the control group (Fig. 4A-iv).

\footnotetext{
Figure 3 (A) CGls selected for the pilot study to assess methylation at paternally expressed imprinted genes in the rat. Schematic diagram of the imprinted loci along with CGI/DMR known to regulate their expression, prepared from information available in the mouse. The EpiTYPER analysis, done as a pilot study to validate the in silico analysis of CGIs in Dlk1 promoter (i, left panel), Dlk1-Meg3 IGDMR (i, right panel), Peg5 (ii), Plag/1 (iii), and Peg3 (iv) genes in a normal embryo and sperm DNA obtained from a control male rat. The epigram depicting the percentage methylation at each $\mathrm{CpG}$ dinucleotide is represented by circles in shades of red ( $0 \%$ methylation) to yellow ( $100 \%$ methylation). The CpG dinucleotide sites that could not be analyzed are depicted as grey circles. Selection of CGls and primer sequences is described in the Materials and Methods section. (B) CGls selected for the pilot study to assess methylation at maternally expressed imprinted genes in the rat. Schematic diagram of the imprinted loci along with CGI/DMR known to regulate their expression, prepared from information available in the mouse. The EpiTYPER analysis, done as a pilot study to validate the in silico analysis of CGls in Grb10 (i), lgf2r(ii), Cdkn1c (iii, left panel), Kcnq1 DMR (iii, middle panel), and Ascl2 (iii, right panel) genes in a normal embryo and sperm DNA obtained from a control male rat. The epigram depicting the percentage methylation at each CpG dinucleotides is represented by circles in shades of red ( $0 \%$ methylation) to yellow ( $100 \%$ methylation). The CpG dinucleotide sites that could not be analyzed are depicted as grey circles. Selection of CGls and primer sequences is described in the Materials and Methods section.
} 
A

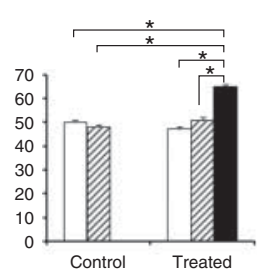

(iv)

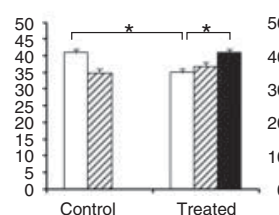

(ii)

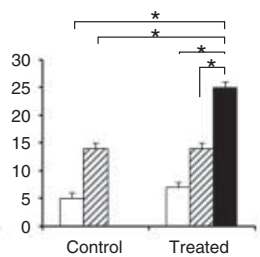

(v)

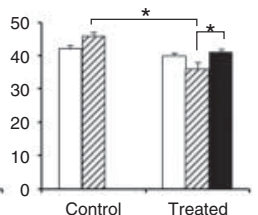

(iii)
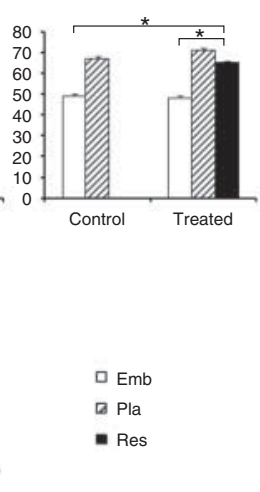

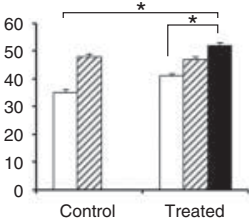

(iv)

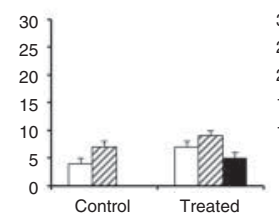

(ii)

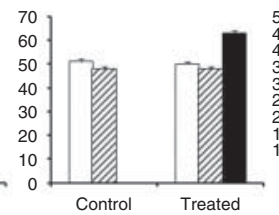

(v)

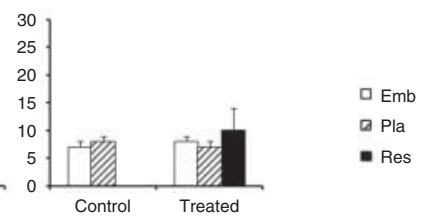

Figure 4 (A) CpG methylation analysis of paternally expressed imprinted genes in rat embryos. Percentage average CpG methylation per amplicon obtained from EpiTYPER analysis of Dlk1 IGDMR (i), Dlk1 (ii), Peg5 (iii), Plag/1 (iv), and Peg3 (v) genes in normal embryo (Emb) and placentae (Pla) at E13 sired by control and tamoxifen-treated male rats $(n=3)$ and resorbing (Res) embryos at E13 sired by tamoxifen-treated male rats $(n=3)$. Values are mean \pm s.D. *Significant difference after Student's $t$-test at $P \leq 0.05$. (B) CpG methylation analysis of maternally expressed imprinted genes in rat embryos. Percentage average CpG methylation per amplicon obtained from EpiTYPER analysis of Igf2r (i), Grb10 (ii), Kcnq1 DMR (iii), Ascl2 (iv), and $C d k n 1 c(v)$ genes in normal embryo (Emb) and placentae (Pla) at E13 sired by control and tamoxifen-treated male rats $(n=3)$ and resorbing (Res) embryos at E13 sired by tamoxifen-treated male rats $(n=3)$. Values are mean \pm s.D. *Significant difference after Student's $t$-test at $P \leq 0.05$.

A significant increase in methylation of Plag/1 DMR was observed in the resorbing embryos when compared with treated normal embryos but was unchanged when compared with normal embryos from control group. A significant decrease in methylation was observed at the Peg3 DMR in the placentae derived from normal embryos of the treated group when compared with those from the control group (Fig. 4A-v). A significant increase in methylation of Peg3 DMR was observed in the resorbing embryos when compared with the placentae of treated group but was unaffected when compared with control group.

\section{Identification of DMRs in maternally expressed imprinted genes and their methylation in embryos sired by tamoxifen-treated rats}

Three of the maternally expressed imprinted genes selected for the study were Grb10, Igf2r, and Kcnq1. In the case of the DMRs for maternally expressed imprinted genes, identification was done as described for paternally expressed genes. The details of the CGI and amplicons used are described in the Materials and Methods section. The results of the pilot study are described below.

Domain 2 identified within the mouse Grb10 gene harbors CGI2, which is hypermethylated in the oocyte and unmethylated in the sperm (Arnaud et al. 2003). A total of eight CpGs located within a CGI of $\sim 1100 \mathrm{bp}$ in the rat Grb10 gene were found to be partially methylated in embryos and hypomethylated in sperm, suggesting it to be a DMR (Fig. 3B-i). Stoger et al. (1993) had identified two regions with the mouse $\lg 2 r$ gene: region 1, which contained the transcription start site; and region 2, which contained in an intron located $27 \mathrm{~kb}$ downstream of the transcription start site. They reported that region 1 acquires methylation after fertilization whereas methylation on region 2 is inherited from the female gamete and hence is the gametic DMR. A total of 11 CpGs located within a CGI of $\sim 895$ bp of the rat lgf2r gene (corresponding to region 1) were found to be partially methylated in embryos and hypomethylated in sperm, suggesting it to be a DMR (Fig. 3B-ii). Four CGls (nucleotide positions 800-2300) were observed in the mouse Igf2r, region 2 (L06446). However, the corresponding region was found to be very poorly conserved in the rat, with a sequence coverage of only $53 \%$ and identity of $80 \%$. Hence, we did not select this region for our study.

Yatsuki et al. (2002) had identified CGI8b as a gametic DMR of the mouse Cdkn1c-Kcnq1ot1 sub-domain, which is unmethylated on the paternal allele. This allele expresses a large non-coding antisense transcript called Kcnq1ot1 (Lit1), which silences the Kcnq1 gene along with neighboring imprinted genes Phld2, Cdkn1c, Kcnq1, and Ascl2 (Mancini-DiNardo et al. 2003, Thakur et al. 2004). A total of 12 CpGs located within a CGI of $\sim 290 \mathrm{bp}$ in the rat Cdkn1c-Kcnq1ot1 domain were found to be partially methylated in embryos and hypomethylated in sperm, suggesting it to be a DMR (Fig. 3B-iii, middle panel). Previously, we had reported downregulation of $C d k n 1 c$ and Ascl 2 transcripts in the resorbing embryos sired by tamoxifen-treated rats (Kedia-Mokashi et al. 2011); hence, in this study, we also assessed the methylation status of the $C d k n 1 c$ and Ascl2 promoters. Yatsuki et al. (2002) had also identified CGI5 within the mouse Cdkn1c promoter, which was methylated on the paternal allele (somatic DMR). A total 
of 31 CpGs located within a CGI of $\sim 1425 \mathrm{bp}$ in the rat $C d k n 1 c$ promoter were found to be hypomethylated in both embryos and sperm (Fig. 3B-iii, left panel). A total of 22 CpGs located within a CGI of $\sim 135 \mathrm{bp}$ in the rat Ascl2 promoter were found to be hypomethylated in both embryos and sperm (Fig. 3B-iii, right panel).

The methylation status of the amplicons given above was assessed in embryos sired by tamoxifen-treated male rats (Fig. 4B). A significant increase in methylation at the lgf2r DMR was observed in the resorbing embryos from the treated group when compared with the normal embryos from both groups (Fig. 4B-i). An increase in methylation was also observed at the Grb10 DMR in the resorbing embryos from the treated group when compared with normal embryos from both groups; however, the difference was not statistically significant due to variations in the methylation levels (Fig. 4B-ii). The methylation at the Kcnq1 DMR (Fig. 4B-iii) and the CPI in the promoters of Ascl2 (Fig. 4B-iv) and Cdkn1c (Fig. 4B-v) genes were comparable in embryos from all the groups.

\section{Methylation of imprinted genes in the sperm of tamoxifen-treated rats}

The putative DMRs of all the four paternally expressed imprinted genes displayed comparable levels of methylation in the sperm of control and tamoxifen-treated rats (Fig. 5A). The DNA methylation levels in sperm ranged

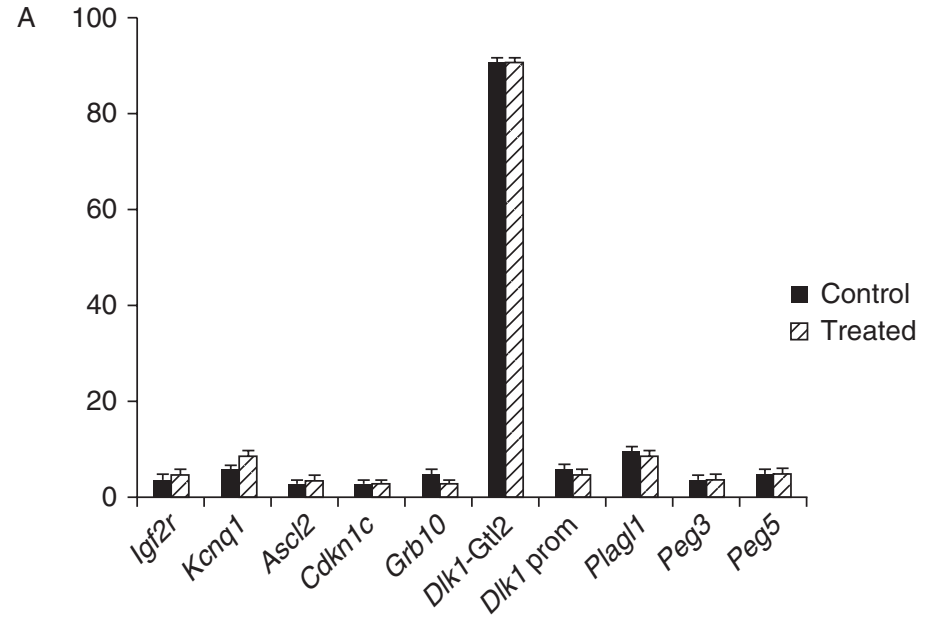

B
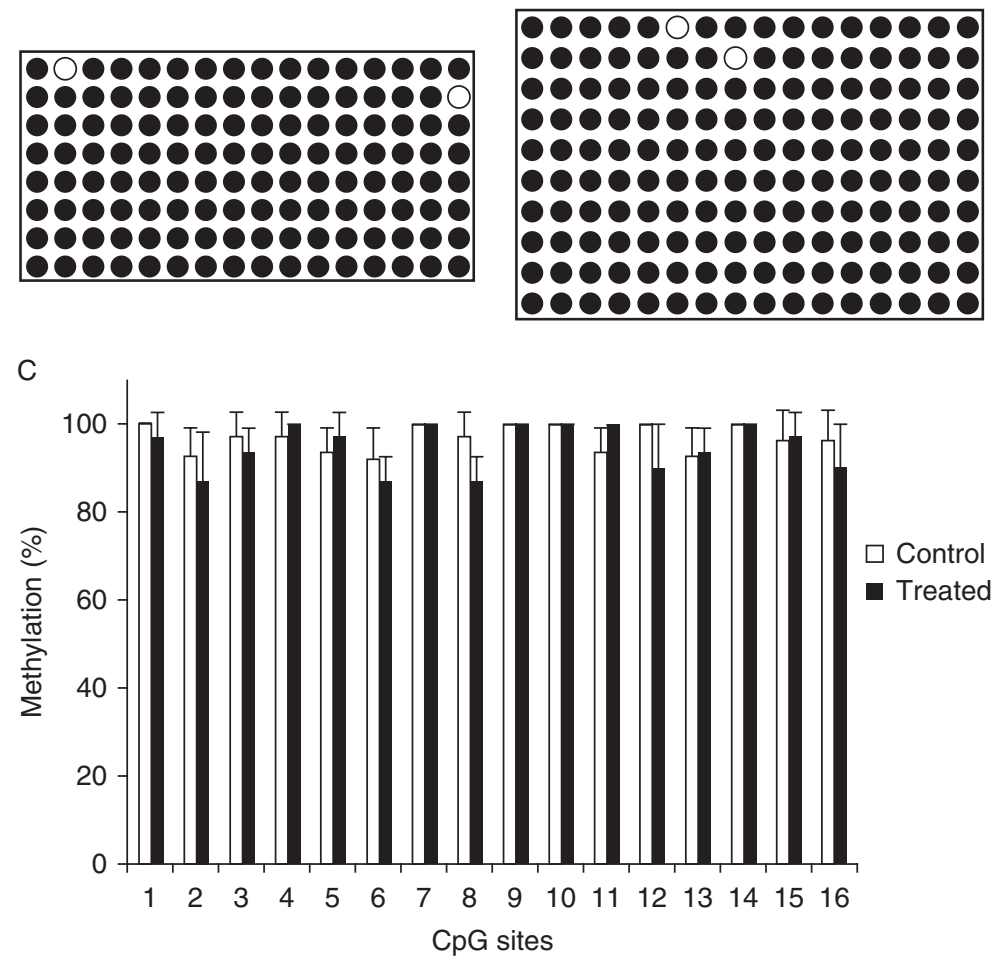

Figure 5 CpG methylation analysis of imprinted genes in rat sperm. (A) Percentage average CpG methylation per amplicon obtained from EpiTYPER analysis of maternally expressed (Igf2r, Kcnq1 DMR, Ascl2, Cdkn1c, and Grb10) and paternally expressed (DIk1 IGDMR, Dlk1, Plagl1, $P e g 3$, and Peg5) genes in sperm obtained from control $(n=10)$ and tamoxifen-treated $(n=9)$ male rats. Values are mean \pm s.D. (B) Representative bisulfite genomic sequencing data obtained from sperm DNA of control and tamoxifen-treated rats. The methylation of $16 \mathrm{CpG}$ sites within the $\sim 396 \mathrm{bp} \mathrm{CGI}$ in the rat DIk1-Meg3 cluster (which was also used for EpiTYPER studies) is represented by circles. Each line represents a single-sequenced clone and eight to ten clones per animal were sequenced. Black and white circles represent methylated and unmethylated cytosines respectively. (C) Analysis of Dlk1-Meg3 IGDMR methylation of individual CpG sites in sperm DNA of control and tamoxifen-treated male rats $(n=3)$. For individual $\mathrm{CpG}$ sites, percentage $\mathrm{CpG}$ sites methylated to the total number of $\mathrm{CpG}$ sites assessed for that site was estimated. The numbers on the $\mathrm{X}$-axis represent the positions of each individual CpG site. Values are mean \pm S.D. Student's $t$-test was used for statistical analysis. 
from 90 to $100 \%$ at the Dlk1-Meg3 DMR and 0 to $10 \%$ at the DMRs of the Plagl1, Peg5, and Peg3 genes, which is similar to that reported in mice. In the case of the maternally expressed imprinted genes, the sperm from the tamoxifen-treated rats displayed comparable levels of methylation when compared with control rats (Fig. 5A). The DNA methylation levels in sperm ranged from 0 to $10 \%$ at the DMRs within the Igf2r, Grb10, and Kcnq1 genes, which was similar to what is reported in mice.

The results obtained for one of the DMRs, namely the Dlk1-Meg3 IGDMR, were reconfirmed using bisulfite sequencing PCR. The methylation of $16 \mathrm{CpG}$ sites within the 2396 bp CGI in the rat Dlk1-Meg3 cluster (which was also used for EpiTYPER studies) was assessed by bisulfite sequencing in the sperm of three rats each from the control and tamoxifen-treated groups. A representative pattern of methylation detected at the $16 \mathrm{CpG}$ sites in control and treated sperm is depicted in Fig. 5B. The average methylation detected is summarized in Fig. 5C. The majority of CpG sites analyzed were methylated in the control group with a mean of $96.6 \%$ methylation. In addition, the tamoxifen-treated group also showed identical levels of methylation with a mean of $94.9 \%$ methylation. No change in methylation at the DIk1-Meg3 IGDMR was detected in the sperm of the tamoxifen-treated group following sequencing of the bisulfite-modified DNA as was observed with EpiTYPER.

\section{Global DNA methylation status of postimplantation embryos}

The 5-methyl cytosine $(5 \mathrm{mC})$ levels in normal embryos sired by control and tamoxifen-treated rats were identical (Fig. 6). The resorbing embryos from the treated group had methylation levels identical to those of the normal embryos of both groups.

\section{Discussion}

We had previously observed aberrant expression of imprinted genes in embryos sired by tamoxifen-treated male rats (Kedia-Mokashi et al. 2011). Therefore, in this study, we assessed the methylation status of several imprinted loci in embryos sired by tamoxifen-treated male rats. Initially, the DMRs of imprinted genes were identified and the selected CGls were subjected to methylation analysis in the sperm of tamoxifen-treated rats and in the embryos sired by them, using EpiTYPER. However, the sperm of tamoxifen-treated rats did not show any change in methylation at the DMRs studied. Hence, the results obtained from EpiTYPER analysis were reconfirmed by bisulfite sequencing of the IGDMR of the Dlk1-Meg3 genes, using sperm from control and tamoxifen-treated rats. Bisulfite sequencing gave results identical to the EpiTYPER analysis, thereby validating its use in the study. Similar results were also observed in

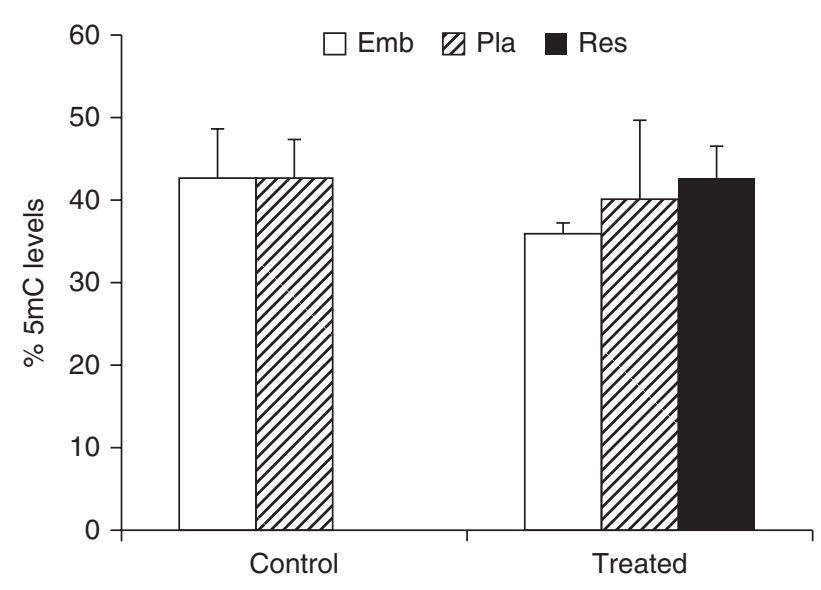

Figure 6 5-Methyl cytosine $(5 \mathrm{mC})$ levels in rat embryos at E13. The mean \pm s.D. of percentage of $5 \mathrm{mC}$ levels in embryo (Emb) and placentae (Pla) at E13 sired by control and tamoxifen-treated male rats $(n=3)$ and resorbing (Res) embryos at E13 sired by tamoxifen-treated male rats $(n=3)$ using Global DNA Methylation Quantification Kit.

another study recently published by our group, on male partners of women undergoing idiopathic recurrent spontaneous abortions (Ankolkar et al. 2013). An increase in methylation at the DMRs of several imprinted genes was observed in the resorbing embryos sired by tamoxifen-treated male rats, suggesting that the epimutations were not transmitted through sperm but could have been acquired post-fertilization. Our earlier studies on gene expression profiling by microarray analysis had shown similar expression profiles for resorbing embryos in both control and treatment groups (Kedia-Mokashi et al. 2011). This indicated that resorbing embryos from both groups might have a similar methylation status. Therefore, methylation status of resorbing embryos from the control group was not done in this study.

The Dlk1-Meg3 cluster is similar to the Igf2-H19 cluster, consisting of a paternally expressed gene and a maternally expressed untranslated RNA in mice and humans. It is also known that the IGDMR, controlling parental-specific expression, is paternally methylated (Wylie et al. 2000, Takada et al. 2002). In this study, the IGDMR of the Dlk1-Meg3 gene was found to be hypermethylated in sperm and partially methylated in the embryos of the control group. Increased methylation at the IGDMR observed in the resorbing embryos sired by tamoxifen-treated male rats should have resulted in increased expression of Dlk1 transcripts. However, downregulation of Dlk1 transcripts was observed in these embryos. This could have occurred due to the observed increase in methylation at the Dlk1 promoter and/or due to the downregulation of Plagl1, which can affect the expression of many imprinted genes through the imprinted gene network (IGN; Varrault et al. 2006). The search for genes frequently co-regulated with Plag/1 identified a significant number of imprinted genes including Meg3, H19, Dlk1, Peg3, Grb10, Igf2, and 
Igf2r (Varrault et al. 2006). Over-expression or downregulation of Plagl1 results in a subsequent change in the levels of the genes in the network (Varrault et al. 2006). The IGN appears to regulate the expression of genes in the network, in the event of alterations in one gene, influencing the overall stability of the system.

The DMR of the mouse Cdkn1C-Kcnq1ot1 subdomain is methylated on the maternal allele (Yatsuki et al. 2002). We found the DMR within the Kcnq1 gene to be hypomethylated in sperm and partially methylated in embryos. This suggests that the DMR identified within the rat Kcnq1 gene is also probably maternally methylated and it might be regulating the expression of genes in the cluster. We had observed downregulation of transcripts of Ascl2, Cdkn1c, and Phlda2 genes in the resorbing embryos (Kedia-Mokashi et al. 2011). Therefore, we assessed the methylation at the CGls within the promoters of $A s c l 2$ and $C d k n 1 c$ genes in addition to the Kcnq1 DMR. However, no change in methylation was observed at the Kcnq1 DMR and/or at the promoters of the Ascl2 and Cdkn1c genes in the resorbing embryos. Decreased expression of genes in this cluster might have also been mediated via abrogation of the IGN in these resorbing embryos.

The DMRs of the remaining imprinted genes investigated in this study are known to be maternally methylated in mice (as stated in the Results section). In this study, the DMRs of Plag/1, Peg5, Peg3, Igf2r, and Grb10 genes were found to be hypomethylated in sperm and partially methylated in embryos, suggesting that they might be maternally methylated in the rat. These genes are important for embryo development (Kagitani et al. 1997, Kikyo et al. 1997, Hiby et al. 2001, Curley et al. 2004, Hitchins \& Moore 2004, Varrault et al. 2006). In the resorbing embryos obtained at E13 from the treatment group, an increase in methylation at the DMRs of Plagl1, Peg5, Peg3, Igf2r, and Grb10 genes was observed, which concurs with the downregulation of their transcripts reported in our earlier studies (KediaMokashi et al. 2011). In addition, the DMRs of Plag/1 and Peg3 genes showed a reduction in methylation in the normal embryos sired by tamoxifen-treated male rats. The reason for this observation is presently not clear.

In order to understand whether the observed methylation changes were global and/or locus specific, we studied the global $5 \mathrm{mC}$ levels in postimplantation embryos sired by tamoxifen-treated male rats. The $5 \mathrm{mC}$ levels were found to be identical in embryos and the placentae of normal embryos sired by control or tamoxifen-treated male rats. In addition, the $5 \mathrm{mC}$ levels observed in the resorbing embryos sired by tamoxifentreated male rats were also comparable to the normal embryos and placentae sired by both groups, suggesting that the methylation changes observed in this study are indeed locus specific. In this study, we have used resorbing embryos as a whole, as it was difficult to distinguish the embryonic and the placental parts in the resorbing embryos. This limits the scope of the study as it cannot be delineated whether aberrant methylation is in the embryo or placenta, or both.

An increase in methylation at DMRs suggests that along with the normally methylated alleles, the

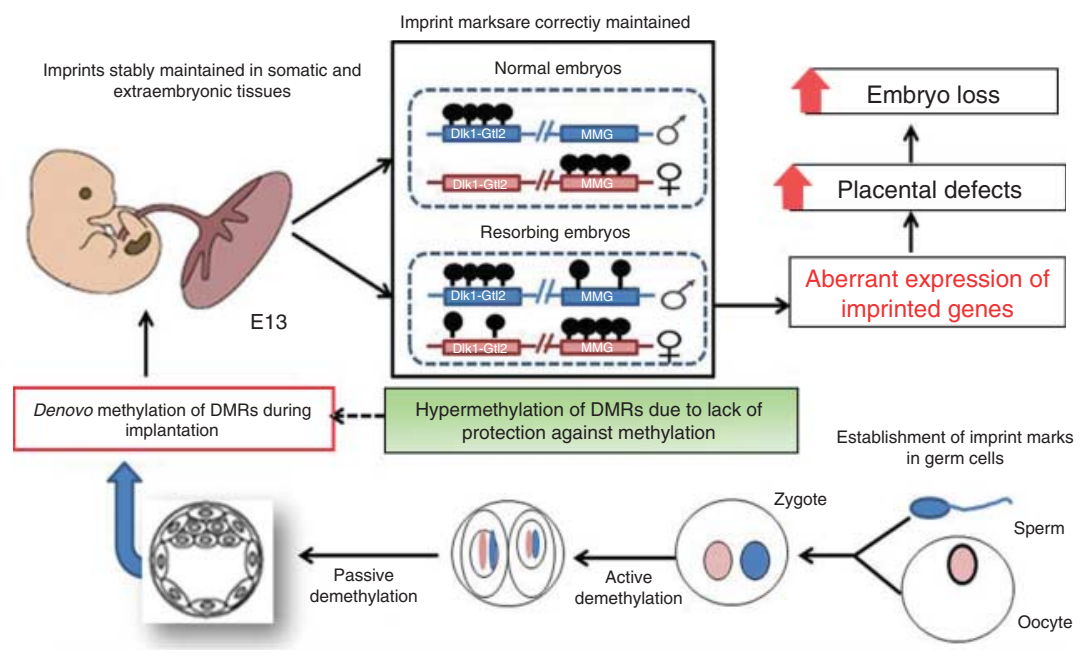

Figure 7 The proposed model of embryo loss involving aberrant DNA methylation at multiple imprinting control regions in embryos sired by tamoxifen-treated male rats. Imprints are established in the gametes. Fertilization is accompanied by the demethylation on the parental genome but imprinted genes resist this demethylation. Subsequently, before implantation, there is de novo DNA methylation but imprinted genes resist de novo methylation, which is then stably maintained in somatic and extra-embryonic tissues. In resorbing embryos obtained from tamoxifen-treated male rats, increase in methylation of Dlk1-Meg3 IGDMR was observed. In addition, there was increased methylation of the CGls identified at other maternally methylated genes (MMG, viz., Plag/1, Peg3, Peg5, lgf2r, and Grb10) in the resorbing embryos. This caused aberrant expression of imprinted genes in these embryos and placental defects, which significantly increased the postimplantation embryos loss. Methylation at CpG dinucleotides is represented by filled circles. 
unmethylated alleles have gained methylation in the resorbing embryos. After fertilization, the preimplantation embryos undergo genome-wide active and passive demethylation. However, the germline imprints appear to be resistant to this methylation reprogramming allowing them to be stably inherited by the offspring (Reik \& Walter 2001). A second wave of developmental reprogramming occurs soon after implantation and is characterized by genome-wide de novo methylation (Reik \& Walter 2001). Recently, several proteins involved in the maintenance of parental-specific imprints have been described, implying that this process might be more precisely regulated than was previously thought (Arnaud 2010). Thus, mechanisms that provide protection to the unmethylated/methylated alleles from getting methylated/demethylated must be active during these periods of genome-wide methylation reprogramming. Thus, deregulation of mechanisms protecting the unmethylated allele from being methylated might have resulted in increased methylation of alleles observed in the resorbing embryos of this study.

Proteins like ZFP57, DPPA3 (STELLA), and MBD3 bind to the DMRs of imprinted genes and assist the DNA methylation machinery in the methylation reprogramming occurring post-fertilization (Nakamura et al. 2007, Reese et al. 2007, Li et al. 2008). Also note that reduced expression of these proteins is associated with hypomethylation of DMRs of imprinted genes (Nakamura et al. 2007, Li et al. 2008). However, in this study, increased methylation of DMRs was observed, which rules out this possibility.

Recently, the CTCF protein that binds to the unmethylated maternal allele of the Igf2-H19 DMR has also been implicated in protecting this allele against acquiring DNA methylation (Schoenherr et al. 2003, Engel et al. 2006). In the absence of CTCF binding, the mouse H19 DMR is susceptible to methylation at the normally unmethylated maternal allele during postimplantation de novo methylation (Engel et al. 2006). Interestingly, ZFP42 (REX1; reduced expression gene 1) is another zinc finger protein that has been implicated in the protection of the unmethylated paternal allele of the Peg3 DMR against DNA methylation during early embryogenesis (Kim et al. 2011). ZFP42 is expressed at high levels in the preimplantation embryo and at modest levels in sperm and the placenta. In addition, Zfp42-null blastocysts exhibit hypermethylation of the DMR of Peg3 and Gnas imprinted domains (Kim et al. 2011). Therefore, downregulation of proteins like ZFP42 could be responsible for the increased methylation at the DMR of imprinted genes in resorbing embryos.

We conclude that the increased methylation at the DMRs of imprinted genes in resorbing embryos sired by tamoxifen-treated male rats could be responsible for their aberrant expression and hence the abrogation of the IGN, collectively causing an increase in postimplantation embryo loss. We hypothesize (Fig. 7) that the levels of proteins involved in the protection of the unmethylated alleles from being methylated during the wave of de novo methylation that occurs postimplantation could have been deregulated in these embryos causing a gain of methylation.

\section{Declaration of interest}

The authors declare that there is no conflict of interest that could be perceived as prejudicing the impartiality of the research reported.

\section{Funding}

The present work (NIRRH/MS/43/12) was partially funded by Board of Research in Nuclear Sciences (BRNS), Department of Atomic Energy (DAE), Government of India through a grant to $\mathrm{N} \mathrm{H}$ Balasinor.

\section{Acknowledgements}

The authors are grateful to Dr Puneet Chandna and his team at AceProbe Pvt. Ltd, New Delhi, for help with EpiTYPER experiments. They are extremely grateful to Mr Suryakant Mandavkar for assistance with animal handling and dosage administration, to Mr Deepak Shelar for the technical help provided, and to Mr Hemant Karekar for help with graphical illustrations. The authors are grateful to Indian Council of Medical Research (ICMR), Government of India, for providing senior research fellowship to $\mathrm{N}$ A Kedia-Mokashi.

\section{References}

Ankolkar M, Salvi V, Warke H, Vundinti BR \& Balasinor NH 2013 Methylation status of imprinted genes DLK1-GTL2, MEST (PEG1), ZAC (PLAGL1) and LINE-1 elements in sperms of normozoospermic men, unlike $\mathrm{H} 19$ imprinting control regions, is not associated with idiopathic recurrent spontaneous miscarriages. Fertility and Sterility 99 1668-1673. (doi:10.1016/j.fertnstert.2013.01.107)

Anway M, Cupp A, Uzumcu M \& Skinner M 2005 Epigenetic transgenerational actions of endocrine disruptors and male fertility. Science 308 1466-1469. (doi:10.1126/science.1108190)

Arnaud P 2010 Genomic imprinting in germ cells: imprints are under control. Reproduction 140 411-423. (doi:10.1530/REP-10-0173)

Arnaud P \& Feil R 2005 Epigenetic deregulation of genomic imprinting in human disorders and following assisted reproduction. Birth Defects Research. Part C, Embryo Today: Reviews 75 81-97. (doi:10.1002/bdrc. 20039)

Arnaud P, Monk D, Hitchins M, Gordon E, Dean W, Beechey CV, Peters J, Craigen W, Preece M, Stanier P et al. 2003 Conserved methylation imprints in the human and mouse GRB10 genes with divergent allelic expression suggests differential reading of the same mark. Human Molecular Genetics 12 1005-1019. (doi:10.1093/hmg/ddg110)

Balasinor N, Parte P, Gill-Sharma MK \& Juneja HS 2001 Effect of tamoxifen on sperm fertilizing ability and pre-implantation embryo development. Molecular Cellular Endocrinology 178 199-206. (doi:10.1016/S03037207(01)00428-2)

Balasinor N, Gill-Sharma MK, Parte P, D'Souza S, Kedia N \& Juneja HS 2002 Effect of paternal administration of an antiestrogen tamoxifen on embryo development in rats. Molecular Cellular Endocrinology 190 159-166. (doi:10.1016/S0303-7207(01)00723-7) 
Bartolomei M \& Ferguson-Smith A 2011 Mammalian genomic imprinting. Cold Spring Harbor Perspectives in Biology 3 a002592. (doi:10.1101/ cshperspect.a002592)

Constancia M, Pickard B, Kelsey G \& Reik W 1998 Imprinting mechanisms. Genome Research 8 881-900. (doi:10.1101/gr.8.9.881)

Coolen MW, Statham AL, Gardiner-Garden M \& Clark SJ 2007 Genomic profiling of CpG methylation and allelic specificity using quantitative high-throughput mass spectrometry: critical evaluation and improvements. Nucleic Acids Research 35 e119. (doi:10.1093/nar/gkm662)

Curley JP, Barton S, Surani A \& Keverne EB 2004 Co-adaptation in mother and infant regulated by a paternally expressed imprinted gene. Proceedings of the Royal Society B: Biological Sciences 271 1303-1309. (doi:10.1098/rspb.2004.2725)

Cuzick J, Powles T, Veronesi U, Forbes J, Edwards R, Ashley S \& Boyle P 2003 Overview of the main outcomes in breast-cancer prevention trials. Lancet 361 296-300. (doi:10.1016/S0140-6736(03)12342-2)

Doerksen T \& Trasler JM 1996 Developmental exposure of male germ cells to 5-azacytidine results in abnormal pre-implantation development in rats. Biology of Reproduction 55 1155-1162. (doi:10.1095/biolreprod55.5.1155)

Doerksen T, Benoit G \& Trasler JM 2000 Deoxyribonucleic acid hypomethylation of male germ cells by mitotic and meiotic exposure to 5-azacytidine is associated with altered testicular histology. Endocrinology 141 3235-3244. (doi:10.1210/en.141.9.3235)

Engel N, Thorvaldsen JL \& Bartolomei MS 2006 CTCF binding sites promote transcription initiation and prevent DNA methylation on the maternal allele at the imprinted H19/lgf2 locus. Human Molecular Genetics 15 2945-2954. (doi:10.1093/hmg/ddl237)

Gill-Sharma MK, Gopalkrishnan K, Balasinor N, Parte P, Jayaraman S \& Juneja HS 1993 Effects of tamoxifen on the fertility of male rats. Journal of Reproduction and Fertility 99 395-402. (doi:10.1530/jrf.0.0990395)

Haines TR, Rodenhiser DI \& Ainsworth PJ 2001 Allele-specific non-CpG methylation of the NF1 gene during early mouse development. Developmental Biology 240 585-598. (doi:10.1006/dbio.2001.0504)

Hess R 1990 Quantitative and qualitative characteristics of the stages and transitions in the cycle of the rat seminiferous epithelium: light microscopic observations of perfusion-fixed and plastic-embedded testes. Biology of Reproduction 43 525-542. (doi:10.1095/biolreprod43.3.525)

Hiby SE, Lough M, Keverne EB, Surani MA, Loke YW \& King A 2001 Paternal monoallelic expression of PEG3 in the human placenta. Human Molecular Genetics 10 1093-1100. (doi:10.1093/hmg/10.10.1093)

Hitchins MP \& Moore GE 2004 Genomic imprinting in fetal growth and development. Expert Reviews in Molecular Medicine 11 1-19.

Jenkins TG \& Carrell DT 2012 The sperm epigenome and potential implications for the developing embryo. Reproduction 143 727-734. (doi:10.1530/REP-11-0450)

John RM, Aparicio SA, Ainscough JF, Arney KL, Khosla S, Hawker K, Hilton KJ, Barton SC \& Surani MA 2001 Imprinted expression of neuronatin from modified BAC transgenes reveals regulation by distinct and distant enhancers. Developmental Biology 236 387-399. (doi:10.1006/dbio.2001.0327)

Kagitani F, Kuroiwa Y, Wakana S, Shiroishi T, Miyoshi N, Kobayashi S, Nishida M, Kohda T, Kaneko-Ishino T \& Ishino F 1997 Peg5/Neuronatin is an imprinted gene located on sub-distal chromosome 2 in the mouse. Nucleic Acids Research 25 3428-3432. (doi:10.1093/nar/25.17.3428)

Kedia N, Gill-Sharma MK, Parte P, Juneja HS \& Balasinor N 2004 Effect of paternal tamoxifen on the expression of insulin-like growth factor 2 and insulin-like growth factor type 1 receptor in the post-implantation rat embryos. Molecular Reproduction and Development 69 22-30. (doi:10.1002/mrd.20159)

Kedia-Mokashi N, Mugasimangalam R, Aiyaz M, Mukherjee S \& Balasinor NH 2011 Aberrant expression of imprinted genes in postimplantation rat embryos. Life Sciences 88 634-643. (doi:10.1016/j.Ifs. 2011.02.005)

Kelly TL \& Trasler JM 2004 Reproductive epigenetics. Clinical Genetics 65 247-260. (doi:10.1111/j.0009-9163.2004.00236.x)

Kelly TL, Li E \& Trasler JM 2003 5-Aza-2' -deoxycytidine induces alterations in murine spermatogenesis and pregnancy outcome. Journal of Andrology 24 822-830. (doi:10.1002/j.1939-4640.2003.tb03133.x)

Kikyo N, Williamson CM, John RM, Barton SC, Beechey CV, Ball ST, Cattanach BM, Surani MA \& Peters J 1997 Genetic and functional analysis of neuronatin in mice with maternal or paternal duplication of distal Chr 2. Developmental Biology 190 66-77. (doi:10.1006/dbio. 1997.8681)

Kim JD, Kim H, Ekram MB, Yu S, Faulk C \& Kim J 2011 Rex1/Zfp42 as an epigenetic regulator for genomic imprinting. Human Molecular Genetics 20 1353-1362. (doi:10.1093/hmg/ddr017)

Kobayashi H, Yamada K, Morita S, Hiura H, Fukuda A, Kagami M, Ogata T, Hata K, Sotomaru Y \& Kono T 2009 Identification of the mouse paternally expressed imprinted gene Zdbf2 on chromosome 1 and its imprinted human homolog ZDBF2 on chromosome 2. Genomics 93 461-472. (doi:10.1016/j.ygeno.2008.12.012)

Li LL, Szeto IY, Cattanach BM, Ishino F \& Surani MA 2000 Organization and parent-of-origin-specific methylation of imprinted Peg3 gene on mouse proximal chromosome 7. Genomics 63 333-340. (doi:10.1006/ geno.1999.6103)

Li X, Ito M, Zhou F, Youngson N, Zuo X, Leder P \& Ferguson-Smith AC 2008 A maternal-zygotic effect gene, Zfp57, maintains both maternal and paternal imprints. Developmental Cell 15 547-557. (doi:10.1016/ j.devcel.2008.08.014)

Lucifero D, Mertineit C, Clarke HJ, Bestor TH \& Trasler JM 2002 Methylation dynamics of imprinted genes in mouse germ cells. Genomics 79 530-538. (doi:10.1006/geno.2002.6732)

Lucifero D, Mann MR, Bartolomei MS \& Trasler JM 2004 Gene-specific timing and epigenetic memory in oocyte imprinting. Human Molecular Genetics 13 839-849. (doi:10.1093/hmg/ddh104)

Mancini-DiNardo D, Steele SJS, Ingram RS \& Tilghman SM 2003 A differentially methylated region within the gene Kcnq1 functions as an imprinted promoter and silencer. Human Molecular Genetics 12 283-294. (doi:10.1093/hmg/ddg024)

Motrich RD, Ponce AA \& Rivero VE 2007 Effect of tamoxifen treatment on the semen quality and fertility of the male rat. Fertility and Sterility $\mathbf{8 8}$ 452-461. (doi:10.1016/j.fertnstert.2006.11.196)

Nakamura T, Arai Y, Umehara H, Masuhara M, Kimura T, Taniguchi $H$, Sekimoto T, Ikawa M, Yoneda Y, Okabe M et al. 2007 PGC7/Stella protects against DNA demethylation in early embryogenesis. Nature Cell Biology 9 64-71. (doi:10.1038/ncb1519)

Nanassy L \& Carrell DT 2008 Paternal effects on early embryogenesis. Journal of Experimental \& Clinical Assisted Reproduction 52. (doi:10.1186/1743-1050-5-2)

Noci I, Chelo E, Salatarelli O, Donaticori G \& Scarselli G 1985 Tamoxifen and oligospermia. Archives of Andrology 15 83-88. (doi:10.3109/ 01485018508986896)

Oakes CC, Kelly TL, Robaire B \& Trasler JM 2007 Adverse effects of 5-aza-2'-deoxycytidine on spermatogenesis include reduced sperm function and selective inhibition of de-novo DNA methylation. Journal of Pharmacology and Experimental Therapeutics 322 1171-1180. (doi:10.1124/jpet.107.121699)

Parker LN, Gray DY, Lai MK \& Levin ER 1986 Treatment of gynecomastia with tamoxifen, a double-blind crossover study. Metabolism 35 705-708. (doi:10.1016/0026-0495(86)90237-4)

Pathak S, Kedia-Mokashi N, Saxena M, D'Souza R, Maitra A, Parte P, Gill-Sharma M \& Balasinor NH 2009 Effect of tamoxifen treatment on global and insulin-like growth factor 2-H19 locus-specific DNA methylation in rat spermatozoa and its association with embryo loss. Fertility and Sterility 91 2253-2263. (doi:10.1016/j.fertnstert.2008. 07.1709 )

Pathak S, Saxena M, D'Souza R \& Balasinor NH 2010 Disrupted imprinting status at $\mathrm{H} 19$ differentially methylated region is associated with resorbed embryo phenotype in rats. Reproduction, Fertility, and Development 22 939-948. (doi:10.1071/RD09154)

Ramsahoye BH, Biniszkiewicz D, Lyko F, Clark V, Bird AP \& Jaenisch R 2000 Non-CpG methylation is prevalent in embryonic stem cells and be mediated by DNA methyltransferase 3a. PNAS 97 5237-5242. (doi:10.1073/pnas.97.10.5237)

Reese KJ, Lin S, Verona RI, Schultz RM \& Bartolomei MS 2007 Maintenance of paternal methylation and repression of the imprinted H19 gene requires MBD3. PLoS Genetics 3 e137. (doi:10.1371/journal. pgen.0030137)

Reik W \& Walter J 2001 Genomic imprinting: parental influence on the genome. Nature Reviews. Genetics 2 21-32. (doi:10.1038/350 47554) 
Schoenherr CJ, Levorse JM \& Tilghman SM 2003 CTCF maintains differential methylation at the Igf2/H19 locus. Nature Genetics 33 66-69. (doi:10.1038/ng1057)

Smith RJ, Arnaud P, Konfortova G, Dean WL, Beechey CV \& Kelsey G 2002 The mouse Zac1 locus: basis for imprinting and comparison with human ZAC. Gene 292 101-112. (doi:10.1016/S0378-1119(02)00666-2)

Stoger R, Kubicka P, Liu CG, Kafri T, Razin A, Cedar H \& Barlow DP 1993 Maternal-specific methylation of the imprinted mouse Igf2 $r$ locus identifies the expressed locus as carrying the imprinting signal. Cell 73 61-71. (doi:10.1016/0092-8674(93)90160-R)

Stouder C \& Paoloni-Giacobino A 2011 Specific transgenerational imprinting effects of the endocrine disruptor methoxychlor on male gametes. Reproduction 141 207-216. (doi:10.1530/REP-10-0400)

Takada S, Paulsen M, Tevendale M, Tsai CE, Kelsey G, Cattanach BM \& Ferguson-Smith AC 2002 Epigenetic analysis of the DIk1-Gt|2 imprinted domain on mouse chromosome 12: implications for imprinting control from comparison with lgf2-H19. Human Molecular Genetics 11 77-86. (doi:10.1093/hmg/11.1.77)

Thakur N, Tiwari VK, Thomassin H, Pandey RR, Kanduri M, Gondor A, Grange T, Ohlsson R \& Kanduri C 2004 An antisense RNA regulates the bidirectional silencing property of the Kcnq1 imprinting control region. Molecular and Cellular Biology 24 7855-7862. (doi:10.1128/MCB.24. 18.7855-7862.2004)

Tomizawa S, Kabayashi H, Watanabe T, Andrews S, Hata K, Kelsey G \& Sasaki H 2011 Dynamic stage-specific changes in imprinted differentially methylated regions during early mammalian development and prevalence of non-CpG methylation in oocytes. Development 138 811-820. (doi:10.1242/dev.061416)

Varrault A, Gueydan C, Delalbre A, Bellmann A, Houssami S, Aknin C, Severac D, Chotard L, Kahli M, Le Digarcher A et al. 2006 Zac1 regulates an imprinted gene network critically involved in the control of embryonic growth. Developmental Cell 11 711-722. (doi:10.1016/j. devcel.2006.09.003)

Wylie AA, Murphy SK, Orton TC \& Jirtle RL 2000 Novel imprinted DLK1/GTL2 domain on human chromosome 14 contains motifs that mimic those implicated in IGF2/H19 regulation. Genome Research 10 1711-1718. (doi:10.1101/gr.161600)

Yatsuki H, Joh K, Higashimoto K, Soejima H, Arai Y, Wang Y, Hatada I, Obata Y, Morisaki H, Zhang Z et al. 2002 Domain regulation of imprinting cluster in Kip2/Lit1 sub-domain on mouse chromosome 7F4/F5: large-scale DNA methylation analysis reveals that DMR-Lit1 is a putative imprinting control region. Genome Research 12 1860-1870. (doi:10.1101/gr.110702)

Received 3 November 2012

First decision 10 December 2012

Revised manuscript received 10 May 2013

Accepted 3 June 2013 